\title{
Novel Experimental Model to Investigate Fluid-Solid Coupling in Coal Seam Floor for Water Inrush
}

\author{
Zhen-hua LI, Shuai-long ZHANG, Feng DU
}

\begin{abstract}
Fluid-solid coupling simulation experiment is an important method for studying water inrush from the coal seam floor. However, the experiment involves seepage-stress coupling problems, and most existing fluid-solid coupling model experiment systems do not meet sealing requirements. To address this issue and to successfully conduct the model experiment, a novel similitude experimental model with excellent sealing was developed for studying fluid-solid coupling during water inrush from the floor of the coal seam. Similitude relationships were also derived using mathematical models for fluid-solid coupling in homogeneous continuum media, and non-hydrophilic fluid-solid coupling similitude materials were prepared. Results show that the experimental system can be used to analyse the variation characteristics of the floor stress and the water pressure, and the mining-induced floor stresses can be divided into three distinct stages, such as the pre-mining stress-increasing stage, the post-mining stress-decreasing stage, and the stress recovery stage. The conclusions obtained in the study have important theoretical value to direct the similar engineering practice.
\end{abstract}

Keywords: coal seam; experimental system; fluid-solid coupling; similitude material; water inrush

\section{INTRODUCTION}

The five largest coalmine water inrushes in the world all occurred in the North of China in the past years. The source of water in these incidents was Ordovician limestone karst water in the floor of the CarboniferousPermian coal system. In addition, with mining depths and mining intensities continuously increasing, the complexity of hydrogeological conditions during mining will also increase. Therefore, water inrush in the coal seam floor becomes a topic worthy of investigation [1]. In the current literature, when coal was mined-out above the confined aquifers, most studies focus on revealing the patterns of water inrush and mining-induced damage of the floor under the coupled actions of seepage and stress. These studies are mostly conducted via theoretical analysis, similitude simulations and numerical calculations [2]. Similitude model experiment, in particular, provides a realistic depiction of the relationship between engineering structures and geological conditions, which provides an accurate simulation of the operational processes on rock masses, so the similitude experiment becomes an effective method for studying large and complex systems.

According to the requirements of similitude theory, fluid-solid coupling model experiments tend to suffer from the following issues: (1) Similitude experiments must satisfy similarity requirements in geometry, boundary conditions, mechanical properties, and rock mass structure. The similitude materials also must meet the similarity requirements in terms of their deformation characteristics and the hydrophysical characteristics. (2) The requirements for the sealing procedures of the similitude equipment are extremely stringent. (3) Requirements for the reliability of the methods are used to monitor changes of the seepage and stress fields [3]. Therefore, similitude experimental studies on this problem remain highly inadequate.

In view of these issues, a novel experimental system with excellent sealing was developed to conduct the fluidsolid coupling studies, and similitude materials were prepared for aquifer that satisfy similarity requirements in terms of their mechanical properties, deformation characteristics and hydrophysical characteristics. The experimental system can simulate the whole process of coal seam floor water inrush, and adjust the in-situ stress and water pressure at any time during the experiment, which has good adaptability to different types of experiments. The findings of this work will therefore establish the basis for the experimental studies on the fluid-solid coupling processes of water inrush from the coal seam floor.

\section{STATE OF THE ART}

The disasters of water inrushes in coalmines are the major threat to the safety and efficiency of production. Many scholars have carried out the related studies on the mechanisms of water inrushes and put forward many countermeasures during mining. For example, Xu D. J. et al. evaluated four floor destruction models containing the water pressure of a floor aquifer and they established the relationship between the floor destruction and risk coefficient [4]. Odintsev, V. N. and Miletenko, N. A. found that spontaneous hydrofracturing was conditioned by natural and induced stresses, hydrostatic pressure of underground water and the mining sequence [5]. Kibria, M. G., et al. conducted a summary regarding the present research emphasizing on the general geologic understanding, hydrogeological, geotechnical, and tectonic setting of the study area, specially ground movement, and water inrush hazards into the mine [6]. Singh, K. B. and Singh, T. N. completed the filling of voids with sand hydraulically to avoid a sudden inrush of water into the under-ground workings through groundmovement induced cracks [7]. To investigate a safety barriers thickness under the threat of adjacent unknown waterlogged mine workings in India, Singh, K. K. K. introduced a new radar having depth of penetration of 60 $\mathrm{m}$ subject to geo-mining conditions of Indian coal mines, and the final trial of the developed radar system was done at the Kachhi Balihari colliery, Dhanbad [8]. However, the research on fluid-structure interaction of water inrush requires to be further studied. 
In fact, there is a close relationship between the water inrush disasters of the mining floors and the seepage expansion of the high-pressure water in the rock stratum, as indicated by the previous research studies regarding this problem. For example, Pang Y. H. et al. found that the crack propagation law and ultimate failure form of the rock specimen, which could reasonably explain the water inrush mechanisms from the mechanical angle [9]. In order to analyze the influence of permeable karst collapse columns (PKCP) on the underground water inrushes resulting from coal mining, $\mathrm{Ma} \mathrm{D}$. et al. adopted a stress and seepage coupling equation to establish a model for the seepage law [10]. Yao B. H. et al. established a fluidsolid coupling model for Karst collapse columns, and obtained such parameters as porosity, seepage, particulate matter concentration, water inrush evolution laws [11]. Shi W. H. et al. conducted a numerical simulation of the excavation processes of the Zhongguan iron mine, based on the monitoring of the underground water site, from the perspective of the mine's previous flooding accident [12]. Liu S. L. et al. simulated the water inrush processes of hidden faults using a FLAC ${ }^{3 \mathrm{D}}$ model, and revealed the uplift height of the closed water of the hidden faults, as well as the formation of water inrush channels [13].

Due to the fact that floor water inrush problems involve high-pressure water seepage, it has been difficult in the past to use common similar materials to conduct intuitive indoor similarity tests. Meanwhile, the current testing system has found difficulties in meeting the sealing requirements, which has resulted in certain impacts on the similarity simulation of water inrush. Some researchers have carried out some studies regarding this problem. In the early years, Kincaid K. and Olson P. developed the similarity materials of the aquiclude to examine the safety mining underneath bodies of water [14]. Shemenda, A. I. obtained good testing effects by making similar materials to simulate plate collision and coal mining under water-rich Eolian sand courses and floor aquiclude [15]. Li S. C. et al. developed the medium- and low-strength rock mass material which could effectively simulate different permeabilities through proportioning testing [16]. Wei L. Y. et al. fabricated a hydrophobic fluid-solid coupled similarity material using paraffin as a cementing agent, and developed a fluid-solid coupled similarity tunnel excavation test [17]. Zhang S. C. et al. used similar materials made of soybean, sand, vaseline, and calcium carbonate to simulate rock with damaged faults, and then physically simulated the formation of a floor fissure in a coal-seam, along with the propagation of hidden faults [18]. The related studies, such as the evolution characteristic of the pressure arch of a double-arch tunnel in the water-rich strata, the deformation and strength characteristics of sandstone with different water contents, and the prediction model of gas quantity emitted from coal face are of reference values for the water inrush analysis [19-21].

To address some of the gaps, we have developed a tightly sealed experimental model system with geometric dimensions, boundary conditions, and loading that adhere to similarity rules, equipped with reliable data monitoring equipment. In addition, the similitude material was prepared, which meets the similarity requirements in terms of solid deformation, physical and mechanical parameters, and the hydrophysical characteristics. The similitude material and experimental model system in combination were used to simulate water inrushes through the coal seam floor, from which the stress curves and water pressure changes of the floor could be obtained.

The remainder of this paper is organized as follows Section 3 describes the structure and functions of the experimental system, and the fluid-solid coupling similarity relationship is derived. The similitude material that satisfies similarity requirements is found through a large number of material mixture experiments and mechanical attribute measurements. Section 4 discusses the applicability of the method through case studies. Section 5 summarizes the conclusions.

\section{METHODOLOGY}

\subsection{Development of an Experimental System}

The geometrical dimensions, boundary conditions, and loading must adhere to certain similarity rules, in accordance with the similarity principle of model experiments. The quality of sealing is also an important aspect of the model experiment on fluid-solid coupling. Therefore, silica gel seals, mechanical seals, and waterproof glue seals were used to ensure the sealing of the model. So tempered glass was used as the primary component of the model-setting compartment to facilitate direct visual observation of the experimental processes. This system consisted of a hydraulic pressure control system, an experimental platform, a data acquisition and the processing system, and its overall dimensions were $1.66 \mathrm{~m} \times 1.70 \mathrm{~m} \times 0.25 \mathrm{~m}$ (width $\times$ height $\times$ thickness). The schematic and photograph of the experimental system are shown in Fig. 1.

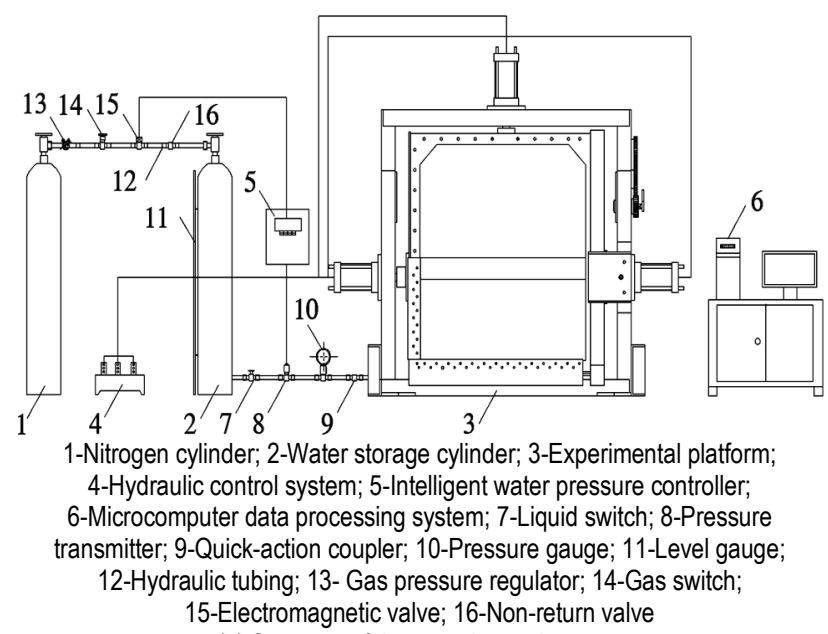

(a) Structure of the experimental system

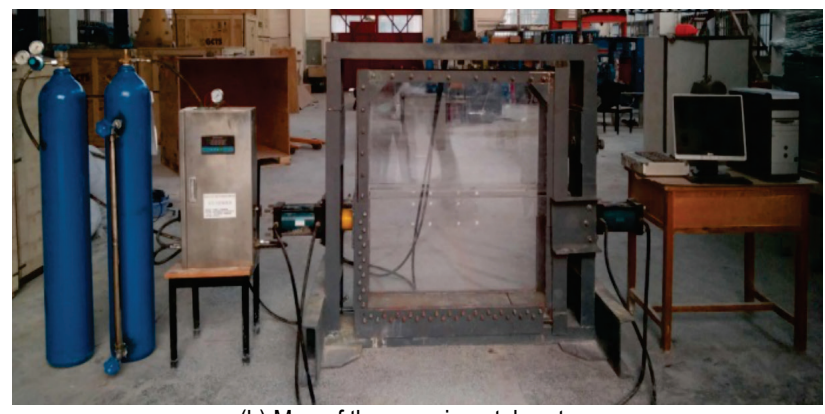

(b) Map of the experimental system

Figure 1 Structure and map of the experiment system 
As shown in Fig. 1, the water pressure control system was developed to address some of the flaws plaguing conventional water pressure control systems, which include unstable transient pressures, high initial costs, vulnerability to damage caused by frequent stop-start operations, and high maintenance costs. The fundamental principle of this system was to use gas pressure to make up for the inadequacies associated with the use of hydraulic pressure alone.

This system was comprised of a high-pressure nitrogen gas cylinder, a water storage cylinder, and an intelligent controller box. Hydraulic tubes, gas regulators, gas switches, electromagnetic valves, and non-return valves linked the high-pressure nitrogen gas cylinder and the water storage cylinder. The water outlet on the bottom of the water storage cylinder had a liquid switch, a pressure transmitter, and a pressure gauge. The pressure transmitter was connected to an intelligent controller, which was in turn connected to an electromagnetic valve. This system was able to regulate the applied pressure between 0-1.25 $\mathrm{MPa}$, and the maximum volume of water that could be supplied at any given instant was $40 \mathrm{~L}$. The intelligent water pressure controller is shown in Fig. 2.

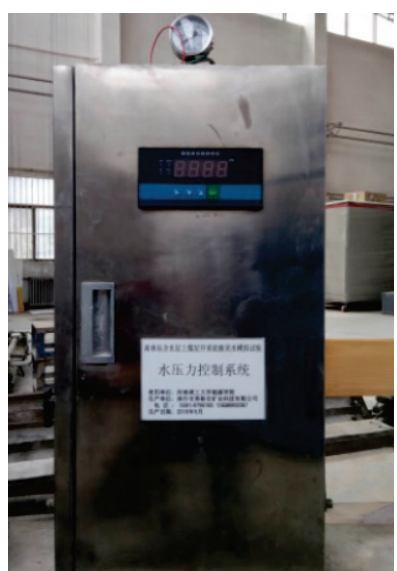

(a) Outside

Figure 2 Intelligent water pressure controlle

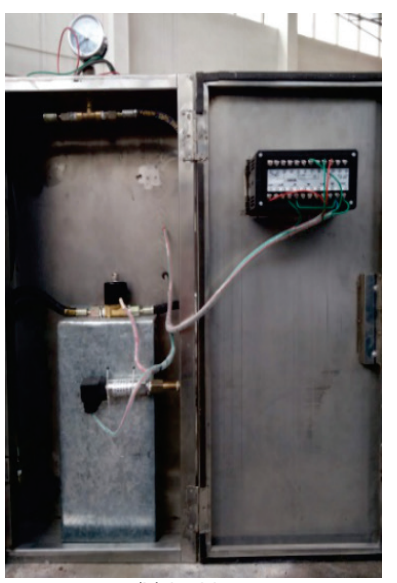

(b) Inside
As shown in Fig. 3, the experimental platform was composed of the reaction frame and the model tank, and the maximum model dimensions that could be accommodated by this system were $1.00 \mathrm{~m} \times 1.00 \mathrm{~m} \times 0$. $20 \mathrm{~m}$ (length $\times$ height $\times$ width). The outer part of the experimental model platform was the reaction frame, which bore the loading of the model, and the height and width of the reaction frame were $1.40 \mathrm{~m}$ and $1.50 \mathrm{~m}$, while the overall height and width of the experimental equipment were $1.70 \mathrm{~m}$ and $1.66 \mathrm{~m}$. Hydraulic cylinders were set up on the top, right and left sides of the reaction frame (model number: MOB-FA125X100). These cylinders were used to apply vertical and horizontal stresses on the model. The hydraulic cylinders were controlled by the hydraulic control system, which could precisely control the pressure within the model. The reaction frame was formed by welding six No. 25 steel channels, and a $10 \mathrm{~mm}$ thick plate was added to the loaded part of the frame to ensure that the reaction frame was sufficiently robust. To increase the amount of room available at the top of the model for applying pressure to the similitude model, the top beam of the reaction frame was designed so that it could be flipped open, and the top beam also had a geared rotational mechanism that could be used to precisely adjust its rotational angle.

The model-setting tank was set up in the middle of the experimental platform. Its outer dimensions were 1.26 $\times 1.18 \times 0.26 \mathrm{~m}$ (width $\times$ height $\times$ thickness), while its inner dimensions were $1.13 \times 1.01 \times 0.20 \mathrm{~m}$ (width $\times$ height $\times$ thickness). The front and back of the model tank were equipped with high-strength transparent plexiglass boards. The plexiglass boards were installed in two pieces, one on the top and one on the bottom, with an opening between the boards. This method facilitated the observation of changes that occur inside the model during an experiment. The model tank was composed of two sections, one on the left and one on the right. The left and right sides of the experimental platform could be attached to each other, which form a cavity with the plexiglass boards on the front and back of the experimental system. This cavity was used to set up the model, and a vertical loading board was set up on the top of the cavity.

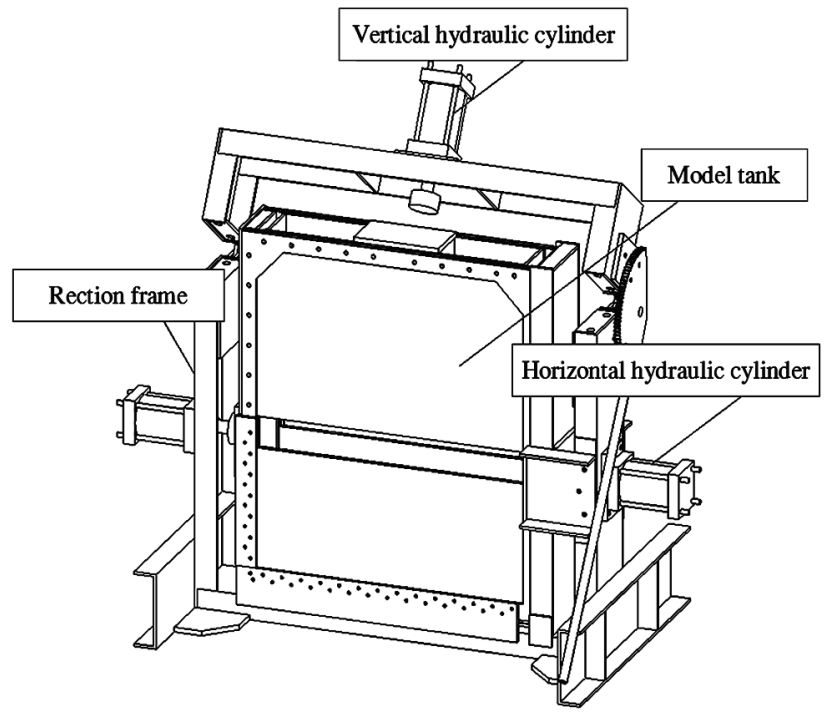

Figure 3 Frame of the experimental platform

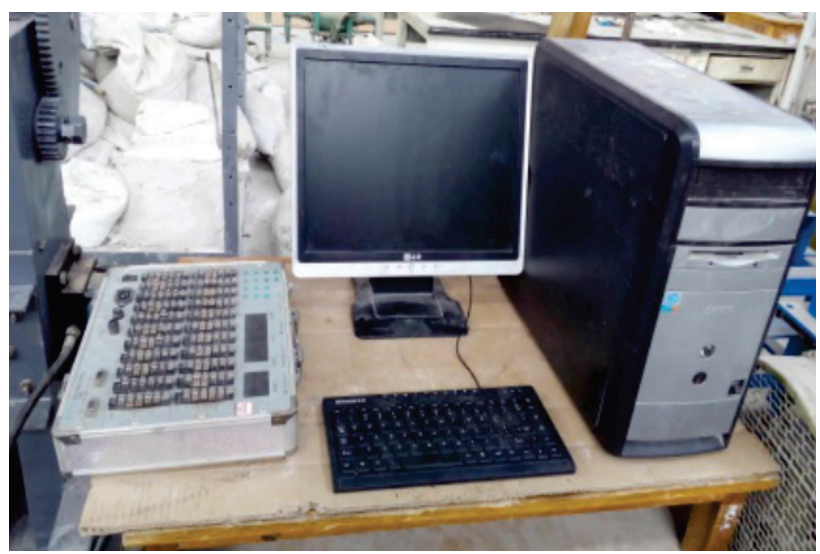

Figure 4 Data processing system

The water tank was set up on the bottom of the left section of the model-setting tank, and it is an $805 \mathrm{~mm}$ long, $180 \mathrm{~mm}$ wide, and $50 \mathrm{~mm}$ high rectangular tank. A water inlet tube was installed inside this tank, which was connected to the water pressure control system, and water inlet holes were also installed on the wall of the water inlet tube. A permeable plate was installed above the 
water tube, which is a steel plate filled with small pores $(80 \mathrm{~mm} \times 180 \mathrm{~mm} \times 4 \mathrm{~mm})$. This plate facilitated direct contact between the analogous materials (coal seam floor) and high-pressure water. To simulate confined aquifers in the floor with varying distributions, in accordance with the real setting that was being simulated, adjustments may be made to the pores of the permeable plate in terms of the number and arrangement of the pores.

As shown in Fig. 4, this system was composed of a DH3818 static strain tester, miniature pressure sensors, a computer, and an analytical software. This monitoring system was able to reliably monitor changes in the strain of the bottom and middle plates during the mining process, and analyse the acquired data

\subsection{Similarity Principles for Fluid-Solid Coupling}

In this work, we used the similarity relationships between model and prototype parameters based on a mathematical model for fluid-solid coupling in continuous media [22]:

Seepage equation is described as

$K_{x} \frac{\partial^{2} p}{\partial^{2} x}+K_{y} \frac{\partial^{2} p}{\partial^{2} y}+K_{z} \frac{\partial^{2} p}{\partial^{2} z}=S \frac{\partial p}{\partial t}+S \frac{\partial e}{\partial t}+W$

In this equation, $K_{x}, K_{y}$, and $K_{z}$ are the permeability coefficients in each of the three coordinate axes (in $\mathrm{cm} / \mathrm{s}$ ), $p$ is the water pressure (in $\mathrm{MPa}$ ), $S$ is the storage coefficient, $e$ is the volumetric strain, $W$ is the source-sink term, and $t$ is the time.

Equilibrium equation is

$$
\sigma_{i j, i}+X_{j}=\rho \cdot \partial^{2} u_{i} / \partial t^{2}
$$

In this equation, $\sigma_{i j, i}$ is the total stress tensor, $\rho$ is the density, and $X_{j}$ is the body force.

Effective stress equation is

$\sigma_{i j}=\bar{\sigma}_{i j}+\alpha \delta_{i j} p$

In this equation, $\bar{\sigma}_{i j}$ is the effective stress tensor, $\alpha$ is the Biot's coefficient, and $\delta_{i j}$ is the Kronecker delta.

The main similarity relationships between the fluidsolid coupling variables of the prototype and model derived using Eqs. (1) to (3) are as follows:

The model similarity relation is:

$C_{G}=C_{\lambda}$

Geometric similarity relation is:

$C_{u}=C_{e} C_{l}$

Gravitational similarity relation is:

$C_{G} C_{e}=C_{\gamma} C_{l}$
Similarity relation of the stresses is:

$C_{\sigma}=C_{\gamma} C_{l}$

Similarity relation of the external loads is:

$C_{h}=C_{\gamma} C_{l}^{3}$

Similarity relation of the water storage coefficients is:

$C_{S}=1 / C_{\gamma} \sqrt{C_{l}}$

Similarity relation of the permeability coefficients is:

$C_{K}=\sqrt{C_{l}} / C_{\gamma}$

In these equations, $C_{G}$ is the similarity scale of the model, $C_{\lambda}$ is the similarity scale of the Lamé constant, $C_{u}$ is the similarity scale of the displacements, $C_{l}$ is the similarity scale of the geometry, $C_{e}$ is the similarity scale of the volumetric strain, $C_{\gamma}$ is the similarity scale of the bulk density, $C_{\sigma}$ is the similarity scale of the stresses, $C_{h}$ is the similarity scale of the external loads, $C_{S}$ is the similarity scale of the water storage coefficient, and $C_{k}$ is the similarity scale of the permeability coefficients.

\subsection{Similitude Material for Fluid-solid Coupling}

To obtain non-hydrophilic similitude materials that have similar mechanical parameters and hydrophysical characteristics as the rocks in aquicludes (limestone and mudstone), sand, talcum powder, and barite powder were chosen as aggregates, with paraffin and vaseline used as cementing agents, with silicon oil used as a regulating agent. The selection of these materials was based on numerous reports made by scholars around the world on similitude materials. A two-piece mould was used to create $\varnothing 50 \times 100 \mathrm{~mm}$ cylindrical standard specimens with different mixture ratios. Compression and hydrophysical tests were then performed on these specimens, from which a material mixture that satisfied the similarity requirements in terms of compressive strength, elastic modulus, permeability coefficient, and water absorbency were discovered.

The prototype compressive strength and permeability coefficients being simulated are as follows: the compressive strength of mudstone and limestone is 20 $\mathrm{MPa}$ and 51.6 MPa, while the permeability coefficients of mudstone and limestone are $1.90 \times 10^{-10} \mathrm{~cm} / \mathrm{s}$ and $0.58 \times 10^{-4} \mathrm{~cm} / \mathrm{s}$, respectively. According to the similarity theories of fluid-solid coupling, the compressive strength and permeability coefficient of the similitude material for mudstone are $0.064 \mathrm{MPa}$ and $0.21 \times 10^{-10} \mathrm{~cm} / \mathrm{s}$, while those of the similitude material for limestone are 0.165 MPa and $0.64 \times 10^{-5} \mathrm{~cm} / \mathrm{s}$, respectively.

The permeability coefficient and water absorbency of the specimens were used to determine whether the hydrophysical characteristics of the similitude material mixtures satisfied the similarity requirements. 


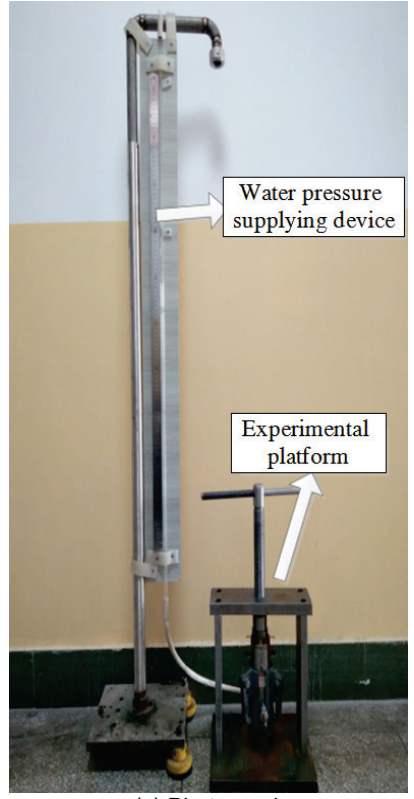

(a) Photograph

(b) Schematic of permeameter

Figure 5 Schematic and photograph of the falling head permeameter

(1) Based on the literature and geotechnical test regulations, the falling head permeability test could be determined to meet the type of similitude material. Hence, as shown in Fig. 5, a falling head permeameter was developed based on experimental principles.

After the permeameter was assembled, the soft tube of the water pressure supplying device was connected to the sleeved water inlet switch. A specified quantity of water was then injected using a glass funnel into the permeameter. After the water level was stabilized, the water inlet was opened so that water would pass through the specimen. When water began to pour out of the drainage cap, a steel ruler was used to mark and record the difference in height between the initial water level in the glass tube and the drainage cap. The hydraulic head was measured at pre-specified time intervals. The permeability coefficient was then calculated using the expression as follows.

$K=\frac{\alpha_{1} L}{A t} \ln \frac{\Delta h_{1}}{\Delta h_{2}}$

where $K$ is the permeability coefficient, $\alpha_{1}$ is the crosssection area of the glass tube, $A$ is the cross-section area of the specimen, $L$ is the length of the specimen, $\Delta h_{1}$ is the initial hydraulic head, and $\Delta h_{2}$ is the hydraulic head after the water level has passed through specimen $t$.

The calculations indicated that the permeability coefficients of the analogous material ratios for mudstone and limestone were $0.15 \times 10^{-10} \mathrm{~cm} / \mathrm{s}$ and $0.33 \times 10^{-5} \mathrm{~cm} / \mathrm{s}$, respectively, which were close to the theoretical calculations and thus satisfied the permeability requirements of this model experiment.

(2) The lower the water absorbency of a material, the weaker its hydrophilicity was. Water absorbency tests were performed on the mudstone and limestone similitude materials described previously. The equation for calculating water absorbency was as follows: $\alpha_{2}=\frac{m_{g}}{m_{s}} \times 100 \%$

where $\alpha_{2}$ is the water absorbency, $m_{s}$ is the mass of the specimen prior to being soaked, and $m_{g}$ is the quantity of water absorbed by the sample after three days of soaking in water.

The calculations showed that the water absorbency of the two different materials only had differed slightly, and only had varied within the range of 0.6-3.1\%. Therefore, these materials were non-hydrophilic. The similitude material mixtures for mudstone and limestone were ultimately determined from tests on various material mixtures, and it had been shown that the physicalmechanical parameters, deformation characteristics and hydrophysical characteristics of the similitude materials met the similarity requirements.

\subsection{New Experimental Model System}

As shown in Fig. 6, the No. 11011 working face of No. 1 coal seam in Zhaogu coal mine in China was chosen as the experimental prototype for this study. The region being simulated in this model study was $200 \mathrm{~m}$ long, $40 \mathrm{~m}$ wide, and $200 \mathrm{~m}$ high, and it encompassed the strata from $-420 \mathrm{~m}$ to $-720 \mathrm{~m}$. The thickness of the coal seam was defined as $6.0 \mathrm{~m}$ from the center of the coal seam. The aquifer lies beneath these strata, whose water level elevation and average water pressure were $30 \mathrm{~m}$ and 4.80 $\mathrm{MPa}$, respectively. This aquifer was simulated in the model experiment using the water pressure control system, using a water tank in tandem. The aquiclude was between $37 \mathrm{~m}$ and $97 \mathrm{~m}$ below the floor of the coal seam. The similitude ratio of the model experiment $C$ was 200 . Based on similarity transformation calculations, the dimensions of the model were $1.00 \mathrm{~m}$ in length (the direction perpendicular to the roadway's axial line), 0.20 $\mathrm{m}$ in width (the direction along the elevation), and $1.00 \mathrm{~m}$ high (the direction parallel to the roadway's axial line). The mechanical parameters of the similitude strata and their material mixtures are given in Tabs. 1 and 2 .

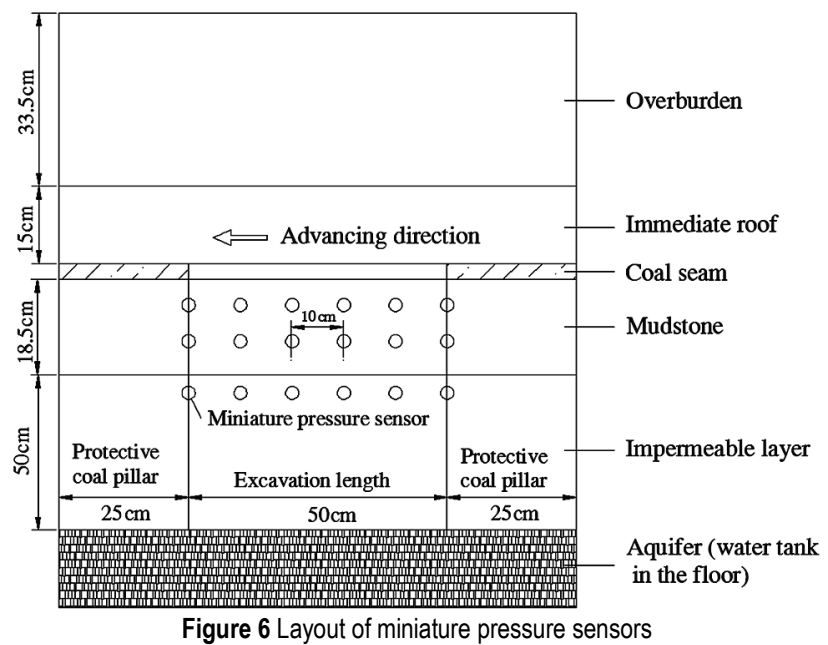

After the model was constructed, the water pressure of the confined aquifer in the floor was calculated as $0.024 \mathrm{MPa}$ according to similarity theory. The vertical 
stress was set to $0.05 \mathrm{MPa}$, while the horizontal stress was set to $0.04 \mathrm{MPa}$. Boring methods were used to excavate the coal seam according to the $1: 200$ similarity ratio conversion, the length of each excavation step was $5 \mathrm{~cm}$, and the open-off cut was performed $25 \mathrm{~cm}$ from the rightsided boundary of the model.

The excavation was paused after each step, and data recording and the next excavation step were only performed after the measurements of the detectors (miniature pressure transmitters) reached the stable state. This continued until the excavation reached the end of the excavation length, $25 \mathrm{~cm}$ from the left-sided boundary of the model. The water pressure control system was used to adjust and measure the change of water pressure, until the water pressure was stabilized during the later stages of this experiment.

Table 1 Physical and mechanical parameters of the materials

\begin{tabular}{|c|c|c|c|c|c|}
\hline Stratum & $\begin{array}{c}\text { Compressive } \\
\text { strength } \\
(\mathrm{MPa})\end{array}$ & $\begin{array}{c}\text { Elastic } \\
\text { modulus } \\
(\mathrm{GPa})\end{array}$ & $\begin{array}{c}\text { Density } \\
\left(\mathrm{g} / \mathrm{cm}^{3}\right)\end{array}$ & $\begin{array}{c}\text { Internal } \\
\text { friction } \\
\text { angle } \\
\left({ }^{\circ}\right)\end{array}$ & $\begin{array}{c}\text { Permeability } \\
\text { coefficient } \\
(\mathrm{cm} / \mathrm{s})\end{array}$ \\
\hline Overburden & 33.25 & 25 & 2.34 & 31 & - \\
\hline $\begin{array}{c}\text { Immediate } \\
\text { roof }\end{array}$ & 20.00 & 26 & 2.10 & 32 & - \\
\hline Coal seam & 16.00 & 4.0 & 1.52 & 20 & - \\
\hline Mudstone & 20.00 & 26 & 2.10 & 32 & $1.90 \times 10^{-10}$ \\
\hline Limestone & 51.60 & 52.1 & 2.50 & 35 & $0.58 \times 10^{-4}$ \\
\hline
\end{tabular}

Table 2 Mixture ratio and paved thickness of the materials

\begin{tabular}{|c|c|c|c|}
\hline Stratum & Mixture materials & Mixture ratio & $\begin{array}{c}\text { Paved } \\
\text { thickness } \\
\text { (cm) }\end{array}$ \\
\hline Overburden & $\begin{array}{c}\text { Sand: Calcium carbonate: } \\
\text { Gypsum: water }\end{array}$ & $1: 0.07: 0.07: 0.16$ & 33.5 \\
\hline $\begin{array}{c}\text { Immediate } \\
\text { roof }\end{array}$ & $\begin{array}{c}\text { Sand: Calcium carbonate: } \\
\text { Gypsum: water }\end{array}$ & $1: 0.10: 0.04: 0.16$ & 15.0 \\
\hline Coal seam & $\begin{array}{c}\text { Sand: Calcium carbonate: } \\
\text { Gypsum: water }\end{array}$ & $1: 0.10: 0.04: 0.16$ & 3.0 \\
\hline Mudstone & $\begin{array}{c}\text { Sand: Precipitate barium } \\
\text { sulphate: Ultrafine } \\
\text { talcum powder: White } \\
\text { vaseline: silicone oil: } \\
\text { Paraffin }\end{array}$ & $\begin{array}{c}1: 0.12: 0.08: 0.04 \\
5: 0.023: 0.06\end{array}$ & 18.5 \\
\hline Limestone & $\begin{array}{c}\text { Sand: Precipitate barium } \\
\text { sulphate: Ultrafine } \\
\text { talcum powder: White } \\
\text { vaseline: silicone oil: } \\
\text { Paraffin }\end{array}$ & $\begin{array}{c}1: 0.12: 0.08: 0.06 \\
: 0.045: 0.02\end{array}$ & 30.0 \\
\hline
\end{tabular}

\section{RESULT ANALYSIS AND DISCUSSION}

\subsection{Analysis of the Stress and Water Pressure in the Floor}

The excavation of the coal seam destabilized the floor strata stresses and produced pattern changes. The distribution of stresses in the floor strata at different depths are reflected in Fig. 7. When the working face was $17.5 \mathrm{~cm}$ away from the open-off cut (approximately $7 \mathrm{~cm}$ below the coal seam), the floor strata stress varied significantly with distance from the coal wall, with the maximum stress reaching $11.4 \mathrm{kPa}$. At $17 \mathrm{~cm}$ below the coal seam, it was observed that the variations in floor strata stress had become smaller in amplitude.

It may be inferred from the analysis of floor strata stresses that the mining-induced damage decreases with depth increasing, while the propagation time increased due to hysteretic effects. The variation in floor stress with the mining of the coal seam may be divided into three distinct stages:

Stage 1: The pre-mining pressure increasing stage. When the excavated zone was $5 \mathrm{~cm}$ ahead of the coal wall, the load bearing forces were still present on the coal wall as it had yet to be damaged by mining, so excavations up to the coal wall would increase the pressure at the coal wall.

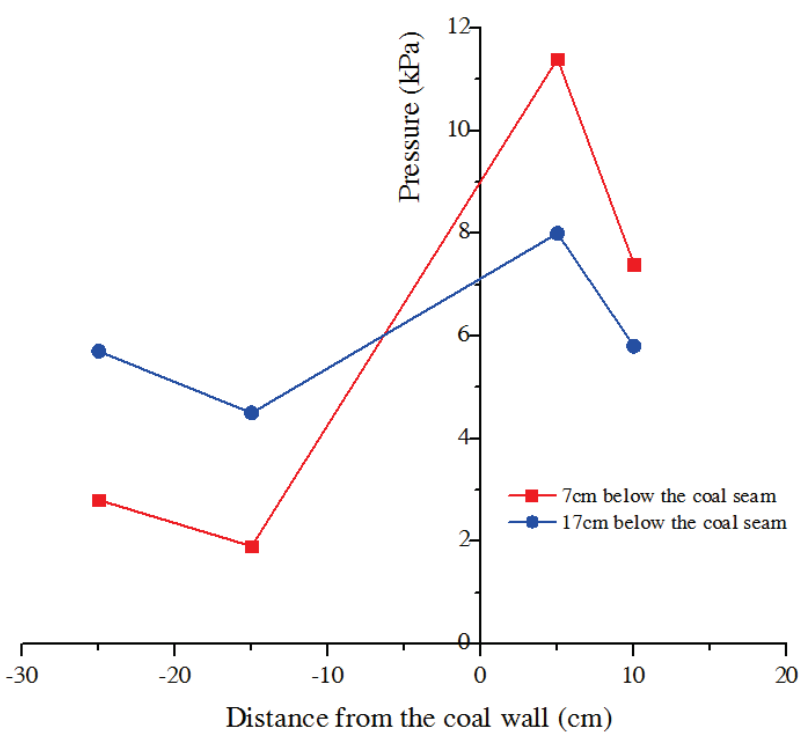

Figure 7 Stress distribution when the working face was about $17.5 \mathrm{~cm}$ from the starting cut

Stage 2: The post-mining pressure relieving stage. In the goaf area in the rear, $15 \mathrm{~cm}$ from the coal wall, the loss of load bearing forces above the floor lead to decrease in floor pressure, the depth of the floor's damage was the greatest within this area.

Stage 3: The stress recovery stage. In the goaf areas more than $15 \mathrm{~cm}$ away from the coal wall, the caving of the roof provided a load bearing force and gradually increased floor stress, the stress in the area $25 \mathrm{~cm}$ away from the coal wall recovered to its pre-mining stress level.

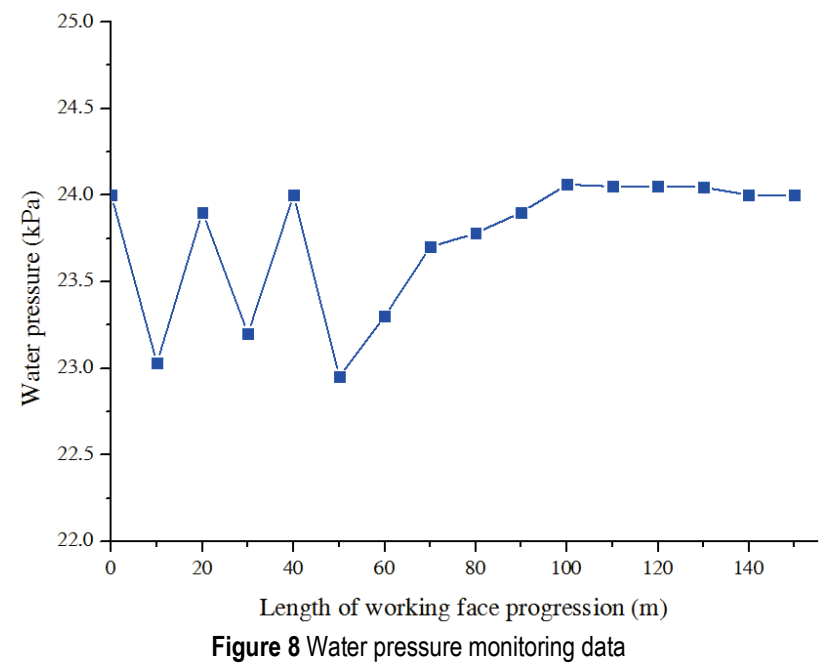

As shown in Fig. 8, the fluctuations in floor stress would decrease with depth (vertical distance from the coal seam) increasing. The water pressure in the floor exhibited two distinct stages as the working face 
progresses from the open-off cut: (1) The water pressure fluctuated between 23-24 MPa over the length between the open-off cut and the point $25 \mathrm{~cm}$ from the open-off cut. This indicated that the fluctuation in water pressure correlates with the stages change in floor stress, and a causal relationship existed between the floor stress and the floor water pressure. (2) After the working face reached the $25 \mathrm{~cm}$ point, the water pressure gradually increased to $24 \mathrm{MPa}$ and tended to stabilize. This indicated that the water pressure exhibited pattern fluctuations due to mining-induced changes in floor stress, and these fluctuations were more obvious when the progression of the working face was between 0-50 m.

\subsection{Comparison between the Stress Analysis and Experimental Results}

The combined action of confined water and pressure made the bottom floor crack damage. As shown in Fig. 9, the upwards transmission of water by the mining-affected confined aquifer led to the formation of an $8 \mathrm{~cm}$-high natural zone for progressive water intrusion. This indicated that the changes in floor stress caused by mining operations led to deformation and damage of the floor. The water pressure of the confined aquifer in the floor simultaneously acted on the floor strata, thus the creating water inrush channels subsequently lead to progressive water intrusion by the confined aquifer via water inrush channels.

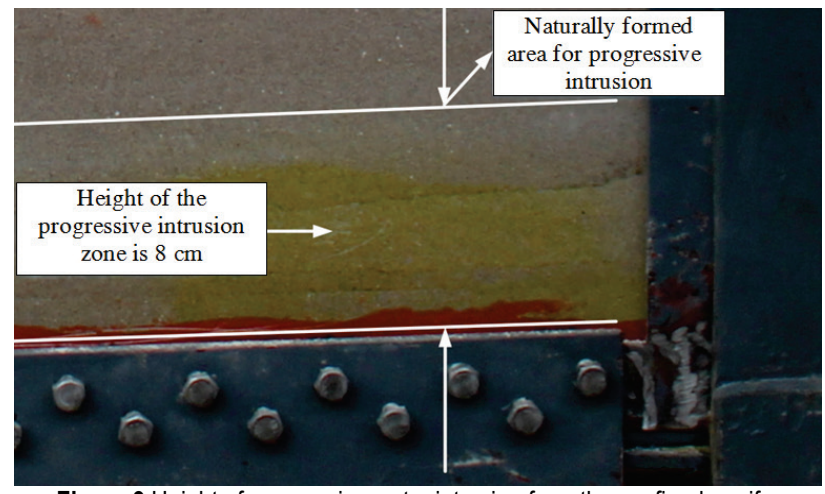

Figure 9 Height of progressive water intrusion from the confined aquifer

The floor stress changed and the confined aquifer water pressure fluctuations triggered by mining activities produced a fluid-solid coupling effect. However, this effect did not cause water outbursts through the working face, but it led to progressive water intrusion. The close fit between the stress curves and experimental results indicated that the experimental model system in this work had excellent sealing, and satisfied the requirements of similitude experiments for water inrushes through coal seam floor. Nonetheless, water inrushes were still possible as the mining depths increased, and the appropriate preventive measures still needed to be put forward to ensure the safety mining.

With the mining depth constantly increasing, the threats of water inrushes from the mine floors were becoming increasingly serious. Therefore, the mechanisms of the floor water inrushes urgently needed to be solved. The experiment revealed the evolution characteristics and failure characteristics of similar materials and deep water inrush channel, which was affected by mining open cut fractured rapidly and higher degree of water inrush probability explained here is prone to water inrush, which had a certain guiding significance for solving practical engineering problems. The results of previous studies showed that during the mining processes of No. 11011 working face of the Zhaogu coal mine in China, the guiding rise zone of the confined water had no effective connection with the destruction zone of the mining floor. There was also an effective aquiclude in the centre, which allowed for the safety mining to be realized. Meanwhile, this also further confirmed that the similar simulation system (non-hydrophilic material and testing device) of floor water inrushes designed in this study could meet the research demands of the disaster-causing mechanisms of floor water inrushes, which provided testing conditions and theoretical support for the safety mining above the confined water under different mining conditions. The experiment process and results fully demonstrated the applicability and reliability of the experimental system.

\section{CONCLUSION}

In order to research on the water inrushes from the floor of the coal seam, this study systematically introduced the structure, advantages, and functions of a self-developed novel type of "fluid-solid coupling simulation test system". By using this system, together with self-developed fluid-solid coupling non-hydrophilic similar simulation material, the floor water inrush model test was conducted. The main conclusions were obtained as follows:

(1) The water pressure control system can accurately simulate the geological environment of confined water in a complicated coal-seam floor. A coordination of the mechanical sealing, silicone rubber sealing, and waterproof sealing using a perspex sheet allow the system to meet the requirements for sealing and visibility.

(2) A new type fluid-solid coupling similarity material through a large number of proportioning tests is prepared according to the deduced similarity relationship. The utilized materials included sand, talcum powder, barite powder, paraffin, vaseline, and silicone oil as raw materials, which are determined to meet such similarity requirements as the model's test strength, elasticity modulus, permeability coefficient.

(3) The novel model test system and non-hydrophilic similarity materials are successfully combined and applied in a floor water inrush model test. The system displays a good sealing performance, and an excellent mechanical performance of the material provides the good testing results.

This novel model test system has a simple structure, stable performance, and good sealing properties, as well as a simple and convenient operation. It serves to lay a foundation for further research regarding floor strata water inrushes resulting from coal-mining processes, as well as stress and strain model testing of fluid-solid coupling planes of various relevant rock strata. However, this model is determined to have limited simulation capabilities for rock strata depth, due to the constraints of dimension, structural strength, and so on. Therefore, it 
will be necessary to conduct further research to improve the abilities of the model regarding the scopes of rock strata depths.

\section{Acknowledgments}

This work was financially supported by the National Natural Science Foundation of China (Nos. 51374093, 51774110), all these are gratefully acknowledged.

\section{REFERENCES}

[1] James, W. L., Wu, Q. \& Zhou, W. F. (2014). New development in theory and practice in mine water control in China. Carbonates \& Evaporites, 29(2), 141-145. https://doi.org/10.1007/s13146-014-0204-7

[2] Meng, Z. P., Li, G. Q. \& Xie X. T. (2012). A geological assessment method of floor water inrush risk and its application. Engineering Geology, 143-144, 51-60. https://doi.org/10.1016/j.enggeo.2012.06.004

[3] Chen, J. T., Yin, L. M., Sun, W. B., Lu, C., Zhang, S. C. \& Sun, X. Z. (2015). Development and application for new solid-fluid coupling similar material of deep floor aquifer. Chinese Journal of Rock Mechanics and Engineering, 34 $\left(\mathrm{S}_{2}\right), 3956-3964$ (in Chinese).

[4] Xu, D. J., Peng, S. P., Xiang, S. Y., Liang, M. X. \& Liu, W. M. (2015). The Effects of caving of a Coal Mine's Immediate Roof on Floor Strata Failure and Water Inrush. Mine Water \& The Environment, 35(3), 1-13.

[5] Odintsev, V. N. \& Miletenko, N. A. (2015). Water inrush in mines as a consequence of spontaneous hydrofracture. Journal of Mining Science, 51(3), 423-434. https://doi.org/10.1134/S1062739115030011

[6] Kibria, M. G., Quamruzzaman, C., Woobaid Ullah, A. S. M. \& Fayazul Kabir, A. K. M. (2012). Effect of longwall mining on groundwater for underground coal extraction in Barapukuria, Bangladesh. Journal of Mines, Metals and Fuels, 60(3-4), 60-66.

[7] Singh, K. B. \& Singh, T. N. (1998). Ground movements over longwall workings in the Kamptee coalfield, India. Engineering Geology, 50(1-2), 125-139. https://doi.org/10.1016/S0013-7952(98)00005-2

[8] Singh, K. K. K. (2016). Delineation of coal barrier thickness in underground coal mines to mitigate inundation hazards-Case studies. Journal of Mines, Metals and Fuels, 64(9), 455-460.

[9] Pang, Y. H., Wang, G. F. \& Ding, Z. W. (2014). Mechanical model of water inrush from coal seam floor based on triaxial seepage experiments. International Journal of Coal Science \& Technology, 1(4), 428-433. https://doi.org/10.1007/s40789-014-0049-7

[10] Ma, D., Miao, X. X., Bai, H. B., Huang, J. H., Pu, H., Wu, Y., Zhang, G. M. \& Li, J. W. (2016). Effect of mining on shear sidewall groundwater inrush hazard caused by seepage instability of the penetrated karst collapse pillar. Natural Hazards, 82(1), 73-93. https://doi.org/10.1007/s11069-016-2180-9

[11] Yao, B. H., Wei, J. P., Wang, D. K., Ma, D. \& Chen, Z. Q. (2013). Numerical study on seepage property of karst collapse columns under particle migration. Computer Modeling in Engineering \& Sciences, 91(2), 81-100.

[12] Shi, W. H., Yang, T. H., Yu, Q. L., Li, Y., Liu, H. L. \& Zhao Y. C. (2017). A study of water-inrush mechanisms based on geo-mechanical analysis and an in-situ groundwater investigation in the Zhongguan Iron Mine, China. Mine Water \& the Environment, 36(3), 409-417. https://doi.org/10.1007/s10230-017-0429-5

[13] Liu, S. L., Liu, W. T. \& Yin, D. W. (2017). Numerical Simulation of the Lagging Water Inrush Process from
Insidious Fault in Coal Seam Floor. Geotechnical \& Geological Engineering, 35(3), 1013-1021. https://doi.org/10.1007/s10706-016-0156-x

[14] Kincaid, C. \& Olson, P. (1987). An experimental study of subduction and slab migration. Journal of Geophysical Research Atmospheres, 921(B13), 13832-13840. https://doi.org/10.1029/JB092iB13p13832

[15] Shemenda, A. I. (1992). Horizontal lithosphere compression and subduction: Constraints provided by physical modeling. Journal of Geophysical Research Solid Earth, 97(B7), 11097-11116. https://doi.org/10.1029/92JB00177

[16]Li, S.C., Wang, K., Li, L. P., Zhang, Q. S., Hu, C., Zhou, Y., Liu, H. L. \& Lin P. (2014). Development and application of an extendable model test system for water inrush simulation in subsea tunnel. Chinese Journal of Rock Mechanics and Engineering, 33(12), 2409-2418. (in Chinese)

[17] Wei, L. Y., Jing, H. W., Xu, B. S. \& Wang, Y. C. (2015). Solid-fluid coupling analogous material test for subsea tunnel. Journal of Central South University (Science and Technology), 46(3), 983-990. (in Chinese)

[18] Zhang, S. C., Guo, W. J., Li, Y. Y., Sun, W. B. \& Yin, D. W. (2017). Experimental simulation of fault water inrush channel evolution in a coal mine floor. Mine Water \& the Environment, 36(3), 443-451. https://doi.org/10.1007/s10230-017-0433-9

[19] Li, C. L., Wang, S. R., Zou, Z. S., Liu, X. L. \& Li, D. Q. (2016). Evolution characteristic analysis of pressure arch of a double-arch tunnel in water-rich strata. Journal of Engineering Science and Technology Review, 9(1), 44-51.

[20] Wang, S. R., Hagan, P., Li, Y. C., Zhang, C. G., Liu, X. L. \& Zou, Z. S. (2017). Experimental study on deformation and strength characteristics of sandstone with different water contents. Journal of Engineering Science and Technology Review, 10(4), 199-203. https://doi.org/10.25103/jestr.104.24

[21] Qiu, J. W., Liu, Z. G., Zhou, L. \& Qin, R. X. (2017). Prediction model of gas quantity emitted from coal face based on PCA-GA-BP neural network and its application. Journal of Power Technologies, 7(3), 169-178.

[22] Hu, Y. Q., Zhao, Y. S. \& Yang, D. (2007). Simulation theory and method of 3D solid-liquid coupling. Journal of Liaoning Technical University, 26(2), 204-206.

\section{Contact information:}

Zhen-hua LI, Ph.D., Associate Professor

School of Energy Science and Engineering,

Henan Polytechnic University,

2001 Century Avenue, Jiaozuo, Henan Province, 454003, China

E-mail: jzlizhenh@163.com

\section{Shuai-long ZHANG, postgraduate}

School of Energy Science and Engineering,

Henan Polytechnic University,

2001 Century Avenue, Jiaozuo, Henan Province, 454003, China

E-mail: 1445035378@qq.com

Feng DU, Ph.D., Lecturer

Corresponding author

School of Energy Science and Engineering,

Henan Polytechnic University,

2001 Century Avenue, Jiaozuo, Henan Province, 454003, China

E-mail: fdu_cumt@126.com 